Article

\title{
Design Optimization Approach of a Large-Scale Moving Framework for a Large 5-Axis Machining Center
}

\author{
Gaoyan Zhong ${ }^{1,2, * \mathbb{D}}$, Ping Liu ${ }^{1}$, Xinliang Mei ${ }^{1}$, Yanqing Wang ${ }^{1,3}$, Fang $X u^{1}$ and \\ Shoufeng Yang $1,4,5, *$ (D)
}

1 College of Engineering, Nanjing Agricultural University, Nanjing 210031, China; liuping@njau.edu.cn (P.L.); meixl@njau.edu.cn (X.M.); pzcyan@126.com (Y.W.); fang160519@126.com (F.X.)

2 State Key Laboratory for Manufacturing Systems Engineering, Xi'an Jiao Tong University, Xi'an 710054, China

3 Canny Elevator Co., Ltd., Suzhou 215213, China

4 Faculty of Engineering, Katholieke Universiteit Leuven (KU Leuven), 3001 Leuven, Belgium

5 Faculty of Engineering and the Environment, University of Southampton, Southampton SO17 1BJ, UK

* Correspondence: gyzhong@njau.edu.cn (G.Z.); shoufeng.yang@kuleuven.be (S.Y.); Tel.: +86-25-5860-6580 (G.Z.)

Received: 21 July 2018; Accepted: 5 September 2018; Published: 10 September 2018

Featured Application: The proposed 3-step design optimization method based on multi-objective optimization and finite element analysis can be considered as a guide for optimizing large-scale moving frameworks to balance the moving mass, material costs, and structural stiffness.

\begin{abstract}
The traditional machine tool design method with metal materials makes large-scale moving structures very heavy, which seriously impacts dynamic performance and results in significant energy consumption. Using sandwich structures of composite materials to replace metal materials is an important strategy for lightweight large-scale moving structures. However, this kind of substitution is generally believed to be difficult because foam-filled sandwich structures usually show nonlinear characteristics and must balance the moving mass, material costs, and structural stiffness. In the present study, we proposed a design optimization approach for a large-scale moving framework in a large 5-axis machining center (L5AMC) considering large dimensions in the $x, y$, and $z$ work space and high machining speed with the aim of minimizing the displacements of the milling head. An improved approach, named the 3-step design optimization, was executed to obtain the optimum framework structures to solve the contradiction between the moving mass, material costs, and structural stiffness. This approach was based on multi-objective optimization and finite element analysis. The structural stiffness of the framework after optimization increased by $89 \%$ compared with before optimization although the mass increased by $6 \%$ and the material costs increased by $9 \%$. A finite element simulation under four given operational loads showed that the displacements of the milling head were all less than the design requirement of $0.25 \mathrm{~mm}$. The results indicated that the proposed 3-step design optimization approach for the optimal design of a large-scale moving framework was feasible and successful. A $40 \mathrm{~m} \times 6 \mathrm{~m} \times 4 \mathrm{~m}$ L5AMC prototype was manufactured, and the actual verification results indicated that the large-scale moving framework fully met the design requirements of the L5AMC and reduced energy consumption.
\end{abstract}

Keywords: large-scale moving structure; 3-step design optimization; sandwich structure; multi-objective optimization; finite element analysis 


\section{Introduction}

The demands for processing complex parts with a free-form surface have resulted in increased use of 5-axis machine tools in automotive, aerospace, die making, and many other industries [1,2]. The role of the machine tool is to ensure the precise movement relationship between the tool and the workpiece. Meanwhile, the moving parts of machine tools consume large amounts of energy [3]. Therefore, precision and energy consumption are guidelines for machine tool design, and are influenced by many factors including the stiffness error caused by structural deformation, assembly error results in tool position error, system dynamic responses under excitation of operational loads, and so on [4-7]. In order to reduce energy consumption, lightweight design and optimization techniques are applied to decrease the moving masses and improve the mass-to-payload ratio [8,9]. Over the last few decades, to improve the accuracy, stiffness, and dynamic performance of machine tools, various lightweight and optimization design methods and strategies have been investigated by many researchers at the early design stage; consequently, structural optimization and lightweight methods have been successfully applied in optimizing dynamical systems and lightweight machines [10-18].

Lightweight design countermeasures are usually taken through appropriate material selection and implementing a structural optimization method. Kim et al. [12] presented a method using composite-foam-resin concrete sandwich structures instead of metal materials for the lightweight design of micro-EDM machines. Li et al. [13] reported a stiffness design of machine tool structures based on a biologically inspired topology optimization method, while Kroll et al. [14] discussed the general influence of lightweight design approaches on energy efficiency in machine tools, as well as restrictions on the maximum mass reduction for structural components. $\mathrm{Li}$ and $\mathrm{Lu}$ [15] reported a design scheme of a lightweight wind turbine tower based on the integration of nanostructured materials produced by a surface mechanical attrition treatment process; the study results revealed that there is sufficient margin for further weight reduction in the traditional wind turbine tower design. In optimization design, Strano et al. [16] proposed an optimization model suitable for press frame designs with respect to energy efficiency. Wu et al. [17] presented an optimization approach for the concept design of machine tools; the results showed that the principal dimensions of all structural parts could be determined while minimizing the weight of the machine and maintaining sufficient stiffness. In order to analyze the dynamic behavior and tool deviations, a dynamic model of a 3-axis gantry milling machine considering axis coupling effects was proposed by Wang et al. [18]. Sandwich structures are commonly used materials for lightweight designs, and their mechanical behaviors are based on their structural features: They are built from two layers, i.e., a stiff and strong skin layer, and a compliant and lightweight core layer [19]. There have been a number of applications in civil and military aircrafts, launch vehicles, wind turbine blades, and marine structures in which composite and sandwich material systems were used as primary structures [20]. Sandwich structures can often sustain large deformations under constant load, enabling them to absorb significant amounts of energy, and to have higher mechanical properties [21-27].

The structure design methods in existing literatures cannot be directly adapted to the design optimization framework for a large 5-axis machining center (L5AMC) due to the large dimensions in the $x, y$, and $z$ work space and high machining speed. The traditional machine tool design method makes the amount of metal used to build the large-scale moving framework account for most of the total weight, and thus, it seriously impacts the dynamic performance and results in significant energy consumption. Hence, using sandwich structures of composite materials to replace metal materials to improve dynamic performance and reduce energy consumption has been a key technology for large-scale moving framework structure design. However, this kind of substitution is generally believed to be difficult because foam-filled sandwich structures usually show nonlinear characteristics and must balance the moving mass, material costs, and structural stiffness. Although studies on lightweight and optimized machine tool structures have long been presented, the design optimization of a large-scale moving framework to improve structural performance and reduce energy consumption still exhibits many challenges, such as how to avert the sandwich panel to generate the well-known 
"curtain effect" [28] due to the large dimensions of the framework structure, how to guarantee high machining speed, lightweight moving mass, and the higher structural rigidity. Therefore, the primary objective of this study was to propose a design optimization framework approach for L5AMC to meet the large dimensions in the work space, and to minimize the displacements of the milling head while maintaining lightweight design for good dynamic drive performance, higher structural stiffness, and low material costs. To achieve these goals, the present study presented an improved approach, named the 3-step design optimization, to obtain the optimum framework structures and solve the contradiction between the moving mass, material costs, and structural stiffness. This approach was based on multi-objective optimization and finite element analysis method.

\section{Overall Layout Analyses}

\subsection{Structural Configuration Analysis}

Most common 5-axis machine tools have three structural configurations: TTTRR, RRTTT, and RTTTR [29], where the three Ts represent translational axes (the $x-, y-$, and $z$-axis) and the two Rs represent rotational axes (the A- and C-axis, or B- and C-axis). Table 1 depicts the structural characteristics of the three configurations.

Table 1. Characteristics of three structural configurations of 5-axis machine tools.

Configuration

From Table 1, it is observed that the TTTRR structure machine tool can be used for fabricating large parts because the three $\mathrm{T}$ and two $\mathrm{R}$ axes can all be set on the cutting tool side, and the workpiece can be fixed. Therefore, the TTTRR 5-axis machine tool has a large bearing capacity. In the same way, the RRTTT structure machine tool can be used for fabricating small parts due to the two R axes being set on the workpiece side. Compared to the TTTRR and RRTTT, the RTTTR structure machine tool can be used for fabricating medium-sized parts. 


\subsection{Overall Layout of the L5AMC}

Based on the above structural configuration analysis, the L5AMC proposed in this paper used the TTTRR structure because it was designed for fabricating large composite material free-form surface parts. The structure of the L5AMC had $40 \mathrm{~m} \times 6 \mathrm{~m} \times 4 \mathrm{~m}$ large translational axes, a $\pm 110^{\circ}$ swing angle of the $\mathrm{B}$-axis, and $\mathrm{a} \pm 360^{\circ}$ turning angle of the $\mathrm{C}$-axis. The design requirements for maximum deformation of the milling head was $0.25 \mathrm{~mm}$ in the $x, y$, and $z$ coordinate directions. Figure 1 presents the overall layout of the L5AMC proposed in this paper.
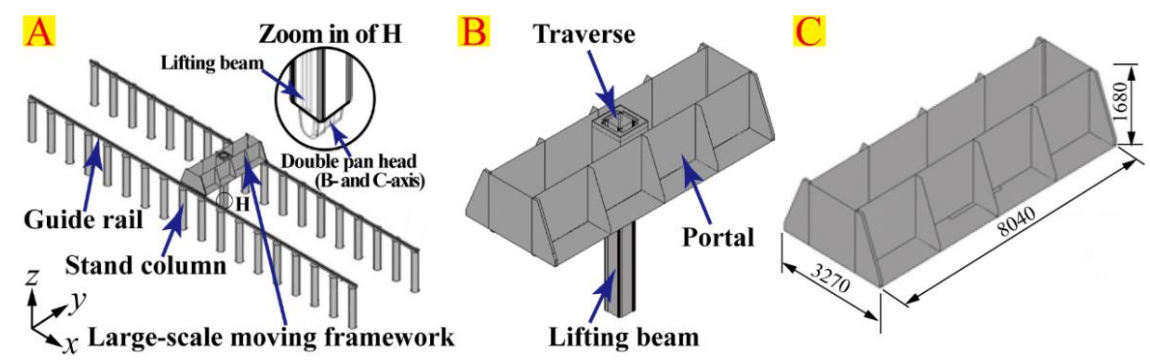

Figure 1. Preliminary design of the L5AMC: (A) overall layout; (B) large-scale moving framework; (C) portal.

\section{Materials and Methods}

\subsection{Design Optimization Methods}

The large-scale moving framework with the $8040 \mathrm{~mm} \times 3270 \mathrm{~mm} \times 1680 \mathrm{~mm}$ portal (Figure 1) was one of the most important components of the L5AMC. According to the traditional machine tool design method, the amount of metal used to build the framework accounts for most of the total weight, which seriously impacts the dynamic performance and results in significant energy consumption. Therefore, the traditional machine tool design method is not suitable for the large-scale moving framework, which requires lightweight design for good dynamic drive performance, higher specific stiffness, and high positioning accuracy and machining precision. To achieve these goals, we presented an improved method, named the 3-step design optimization. It included the following three steps: (1) Using sandwich structures of composite materials to replace metal materials to achieve lightweight design of the large-scale moving framework; (2) multi-objective optimization of sandwich structures to solve the contradiction between the moving mass, material costs, and structural stiffness; and (3) design optimization framework structures to minimize the displacements of the milling head based on finite element analysis (FEA) method.

\subsection{General Model of the Sandwich Structure}

In this study, we first replaced metal materials with sandwich structures of composite materials to reduce the mass of the framework, and by doing so, guaranteeing the structural stiffness as high as possible based on multi-objective optimization and FEA. Figure 2 presents the general model of the sandwich structure of composite materials.
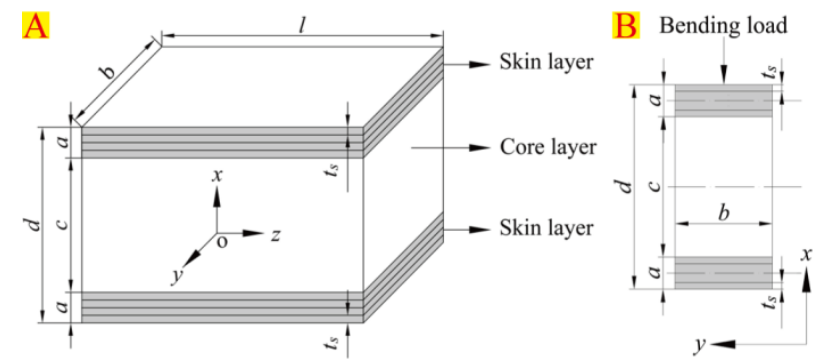

Figure 2. General model of sandwich structure: (A) in three dimensions; (B) in the $z$-direction. 
From Figure 2, it is observed that following relationships exist:

$$
\left\{\begin{array}{l}
a=t_{s} n \\
d=2 a+c
\end{array}\right.
$$

where $a$ and $c$ represent the thickness of the skin layer and core layer, respectively; $d, b$, and $l$ represent the total thickness, width, and length of the sandwich structure, respectively; $t_{s}$ represents the thickness of each skin layer; and $n$ represents the layer number of the skin layer.

\subsection{General Method for Optimization of Sandwich Structural Parameters}

To balance the moving mass, material costs, and structural stiffness while considering nonlinear characteristics of the foam-filled sandwich structures, the optimal sandwich structural parameters were obtained by employing the multi-objective optimization method. The general formula for multi-objective optimization is as follows:

$$
\begin{array}{ll}
\min _{x} & F(x)=\left(f_{1}(x), f_{2}(x), f_{3}(x), \ldots, f_{i}(x)\right)^{T} \\
& x_{i}^{l} \leq x_{i} \leq x_{i}^{u} \quad i=1, \ldots N
\end{array}
$$

where $f_{1}, f_{2}, f_{3}, \ldots, f_{i}$ are the objective functions; $x_{i}^{l}$ and $x_{i}^{u}$ are the lower and upper bounds of the design variables; and $N$ is the number of variables.

In general, conflict occurs when several objectives are considered within the optimization, meaning that an increased performance in one objective may lead to decreased performance in others [30]. Therefore, there is a trade-off between objectives. In this study, multi-objective optimization acted to solve the contradiction between the mass, material costs, and structural stiffness.

For the general model of the sandwich structure (Figure 2), the equivalent bending stiffness (EI) of the sandwich panel can be expressed as follows [12]:

$$
\left\{\begin{aligned}
E I= & E_{S} I_{S}+E_{c} I_{c} \\
E_{S} I_{S} & =E_{s}\left[\frac{b d^{3}}{12}-\frac{b c^{3}}{12}\right] \\
& =E_{s}\left[\frac{a b(a+c)^{2}}{2}+\frac{b a^{3}}{6}\right] \\
E_{c} I_{c} & =E_{c} \frac{b c^{3}}{12}
\end{aligned}\right.
$$

Furthermore, the equivalent mass of the sandwich panel can be expressed as:

$$
\left\{\begin{array}{l}
m=m_{s}+m_{c}=V \rho \\
m_{s}=V_{s} \rho_{s}=2 a b l \rho_{s} \\
m_{c}=V_{c} \rho_{c}=c b l \rho_{c}
\end{array}\right.
$$

Similarly, the material cost $(C)$ can be expressed as follows:

$$
\left\{\begin{array}{l}
C=C_{s}+C_{c}=m \times C_{k g} \\
C_{s}=m_{s} C_{k g s} \\
C_{c}=m_{c} C_{k g c}
\end{array}\right.
$$

where subscripts $s$ and $c$ represent the skin material and core material, respectively; $E$ represents young's modulus; $I$ represents moment of inertia; $m$ represents the mass; $\rho$ represents the equivalent mass density; $V$ represents the total volume; and $C_{k g}$ represents the material cost per kg.

Table 2 depicts the objective functions defined within the size optimization. 
Table 2. Objective functions defined within the size optimization.

\begin{tabular}{ccc}
\hline Objective & Function & Description \\
\hline Minimize & Mass & Defined by Equation (4) \\
Minimize & Material costs & Defined by Equation (5) \\
Maximize & Stiffness & Defined by Equation (3) \\
\hline
\end{tabular}

\subsection{Materials for Sandwich Structure}

Skin layer materials were preliminary selected as carbon fiber (CF), glass fiber (GF), and Al, respectively; core layer materials were preliminary selected as polyvinyl chloride (PVC) foam, and polyurethane (PUR) foam, respectively. The design variables were $n, t_{s}$ and $c$. Table 3 lists the above materials' properties used within the optimization studies.

Table 3. Materials properties and the costs used within the optimization studies.

\begin{tabular}{ccccc}
\hline \multirow{2}{*}{ Material Type } & \multicolumn{3}{c}{ Material Properties } & \multirow{2}{*}{$C_{\boldsymbol{k g}}$ (USD/kg) } \\
\cline { 2 - 4 } & $\boldsymbol{E} \mathbf{( G P a )}$ & $\boldsymbol{G} \mathbf{( G P a )}$ & $\boldsymbol{\rho} \mathbf{( \mathbf { k g } / \mathbf { m } ^ { \mathbf { 3 } } )}$ \\
\hline CF & 200 & 4.4 & 1650 & 60 \\
GF & 16.7 & 2.237 & 1704 & 15 \\
Al & 70 & 26.1 & 2700 & 6 \\
PVC foam & 0.13 & 0.035 & 100 & 55 \\
PUR foam & 0.055 & 0.021 & 150 & 22 \\
\hline
\end{tabular}

Note: Data were taken from the literature [30,31], and costs were converted from SEK to USD.

\section{Modeling and Stiffness Analysis}

\subsection{Sandwich Structural Parameters Optimization}

The multi-objective optimization has a rather different perspective compared with single-objective optimization. There is only one global optimum in single-objective optimization, but in multi-objective optimization there is a set of solutions, named the Pareto-optimal set, which are considered to be equally important; all of them constitute global optimum solutions [32-34]. Non-dominated Sorting Genetic Algorithm II (NSGA-II) is regarded as an effective and efficient multi-objective optimization technique in various applications $[33,34]$. To optimize the sandwich structures, multi-objective optimization of sandwich structural parameters based on an improved NSGA-II algorithm were conducted using MATLAB R2013a software according to Equations (3)-(5), where the lower and upper bounds of the design variables were: $0.1 \leq t_{s} \leq 1.0,1 \leq n \leq 10$ and $20 \leq c \leq 30$ respectively. The detailed optimization process of the sandwich structural parameters will be reported in another investigation. Table 4 listed two of the optimal results from the Pareto-optimal set of the sandwich structural parameters in combination with commercial specifications of skin layer and core layer materials for further framework structural optimization.

Table 4. Two of the optimal results of the sandwich structure of the portal.

\begin{tabular}{|c|c|c|c|c|c|c|}
\hline \multirow{2}{*}{ Name } & \multirow{2}{*}{ Material Type } & \multicolumn{3}{|c|}{ Parameters } & \multicolumn{2}{|c|}{ Properties } \\
\hline & & $n$ & $t_{s}(\mathrm{~mm})$ & $c(\mathrm{~mm})$ & $E I\left(\mathrm{Nm}^{2}\right)$ & $m\left(\mathrm{~kg} / \mathrm{m}^{2}\right)$ \\
\hline Composite plate & $\mathrm{CF}+\mathrm{PVC}$ & 4 & 0.57 & 24 & 0.27 & 8.104 \\
\hline Reinforced composite plate & $\mathrm{CF}+\mathrm{PVC}$ & 8 & 0.57 & 20 & 0.47 & 14.770 \\
\hline
\end{tabular}

Figure 3 presented the schematic diagrams of the two types of sandwich panels, where, $\left[0^{\circ}-45^{\circ}\right.$ $\left.45^{\circ} 0^{\circ}\right]$ and $\left[0^{\circ} 0^{\circ}-45^{\circ} 0^{\circ} 0^{\circ} 45^{\circ} 0^{\circ} 0^{\circ}\right]$ represent orientation angle of $\mathrm{CF}$ in per layer. Zero degree orientation angle is for axial load ( $z$-direction load in the present study), and $\pm 45^{\circ}$ orientation angles are for shear load ( $x$-direction or $y$-direction load in the present study). 

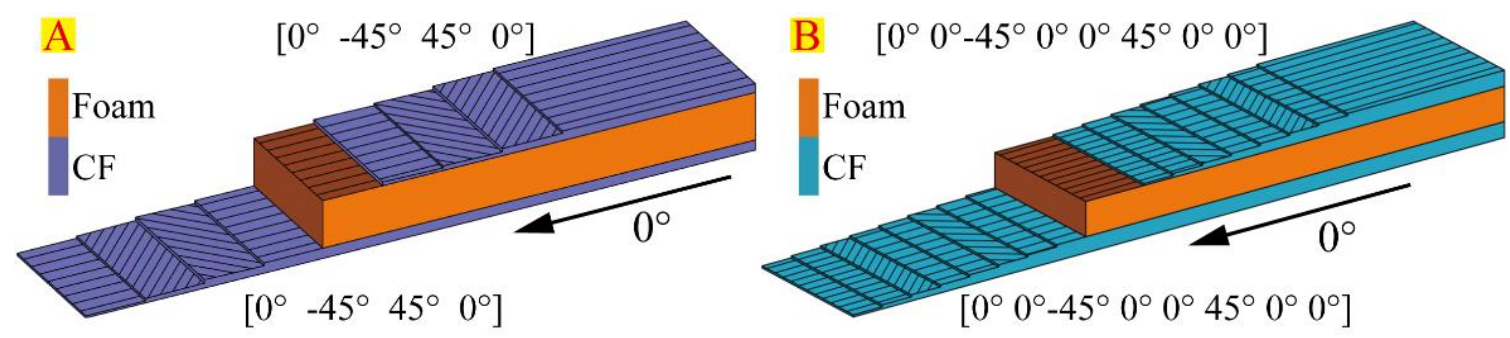

Figure 3. Two types of sandwich panels: (A) composite plate; (B) reinforced composite plate.

\subsection{Modeling for Large-Scale Moving Framework}

In order to analyze the maximum displacements of the milling head, models of the large-scale moving framework were established (Figure 4). They were composed of aluminum alloy beams (used internal support structure), composite plates, and small aluminum alloy panels placed on the left and right sides. Different aluminum alloy beams were used for mounting purposes and to enhance system stiffness to avert the sandwich panel generating the well-known "curtain effect" (see Figure A1) due to the large dimensions of the portal. Table A1 lists the major material parameters used for the design of the large-scale moving framework.
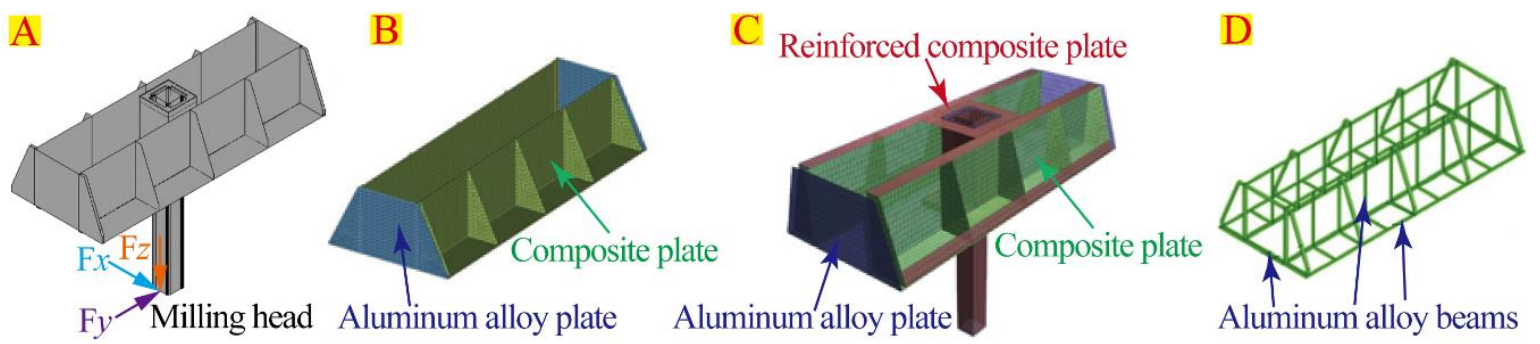

Figure 4. Models of the framework: (A) Three-dimensional model; (B) finite element model of portal before optimization; (C) finite element model after optimization; (D) support model.

In these models, $F_{x}, F_{y}$, and $F_{z}$ represent loads acting on the milling head in the $x, y$, and $z$ directions, respectively. The milling head was mounted at the end of the lifting beam.

\subsection{System Stiffness Analysis}

It is well known that the system stiffness of the framework $K$ can be expressed as follows:

$$
\left\{\begin{array}{l}
K_{x}=\frac{F_{x}}{\Delta x} \\
K_{y}=\frac{F_{y}}{\Delta y} \\
K_{z}=\frac{F_{z}}{\Delta z}
\end{array}\right.
$$

where $K_{x}, K_{y}$, and $K_{z}$ represent the system stiffness of the framework in the three coordinate directions; $F_{x}, F_{y}$, and $F_{z}$ represent loads acting on the milling head in the three coordinate directions; and $\Delta x, \Delta y$, and $\Delta z$ represent the displacement of the milling head in the three coordinate directions.

Consequently, minimizing the displacements of the milling head is a key step to ensuring system stiffness, positioning accuracy, and machining precision when the loads are given. Table 5 lists the four given values of operational loads for further design optimization of the framework. 
Table 5. Operational loads for the milling head in the manufacturing process.

\begin{tabular}{|c|c|c|c|c|}
\hline No & Name & Operational Loads & Description & Given Value \\
\hline 1 & Load 1 & G & $\begin{array}{l}G=m g \text { ( } m \text { represents mass of the } \\
\text { framework, } g \text { represents gravity } \\
\text { acceleration) }\end{array}$ & - \\
\hline 2 & Load 2 & $G+F_{x}$ & $\begin{array}{l}G=m g \text { and } F_{x}=m a_{x}\left(a_{x} \text { represents }\right. \\
\text { acceleration in the } x \text {-direction. The } \\
\text { maximum } a_{x} \text { is for starting and stopping) }\end{array}$ & $a_{x \max }=1.5 \mathrm{~m} / \mathrm{s}^{2}$ \\
\hline 3 & Load 3 & $G+F_{y}$ & $\begin{array}{l}G=m g \text { and } F_{y}=m a_{y}\left(a_{y} \text { represents }\right. \\
\text { acceleration in the } y \text {-direction. The } \\
\text { maximum } a_{y} \text { is for starting and stopping) }\end{array}$ & $a_{y \max }=1.5 \mathrm{~m} / \mathrm{s}^{2}$ \\
\hline 4 & Load 4 & $G+F_{z}$ & $\begin{array}{l}G=m g \text { and } F_{z}=m a_{z}\left(a_{z} \text { represents }\right. \\
\text { acceleration in the } z \text {-direction. The } \\
\text { maximum } a_{z} \text { is for starting and stopping) }\end{array}$ & $a_{z \max }=1.5 \mathrm{~m} / \mathrm{s}^{2}$ \\
\hline
\end{tabular}

\section{Optimization Design for the Framework}

\subsection{Optimization Designs for the Portal}

In order to determine the optimum structure of the large-scale moving framework, the portal structure was first optimized based on the FEA method after the sandwich structural parameters optimization. The FEA was carried out to analyze the maximum deformation of the portal under the given operational loads. Boundary conditions are use to describe the interaction of the structure with its environment as shown in Figure 5, where vertical support of the portal is applied as fixed vertical displacement at marked positions, as shown in Figure 5A. Horizontal support of the portal is applied as fixed displacement in $x$-direction and fixed displacement in $y$-direction at marked positions, as shown in Figure 5B. The weight of the traverse and lifting beam is applied as forces in their center of gravity (COG), as shown in Figure 5C. The acceleration for these two components is also applied at their center of gravity. The COG is rigidly linked to the connection points of the portal. Similarly, the weight of the milling head was considered by a point mass at its mass origin. The point mass was connected to all gravity and acceleration loads, as shown in Figure 5D. The top view of all boundary conditions is shown in Figure 5E.

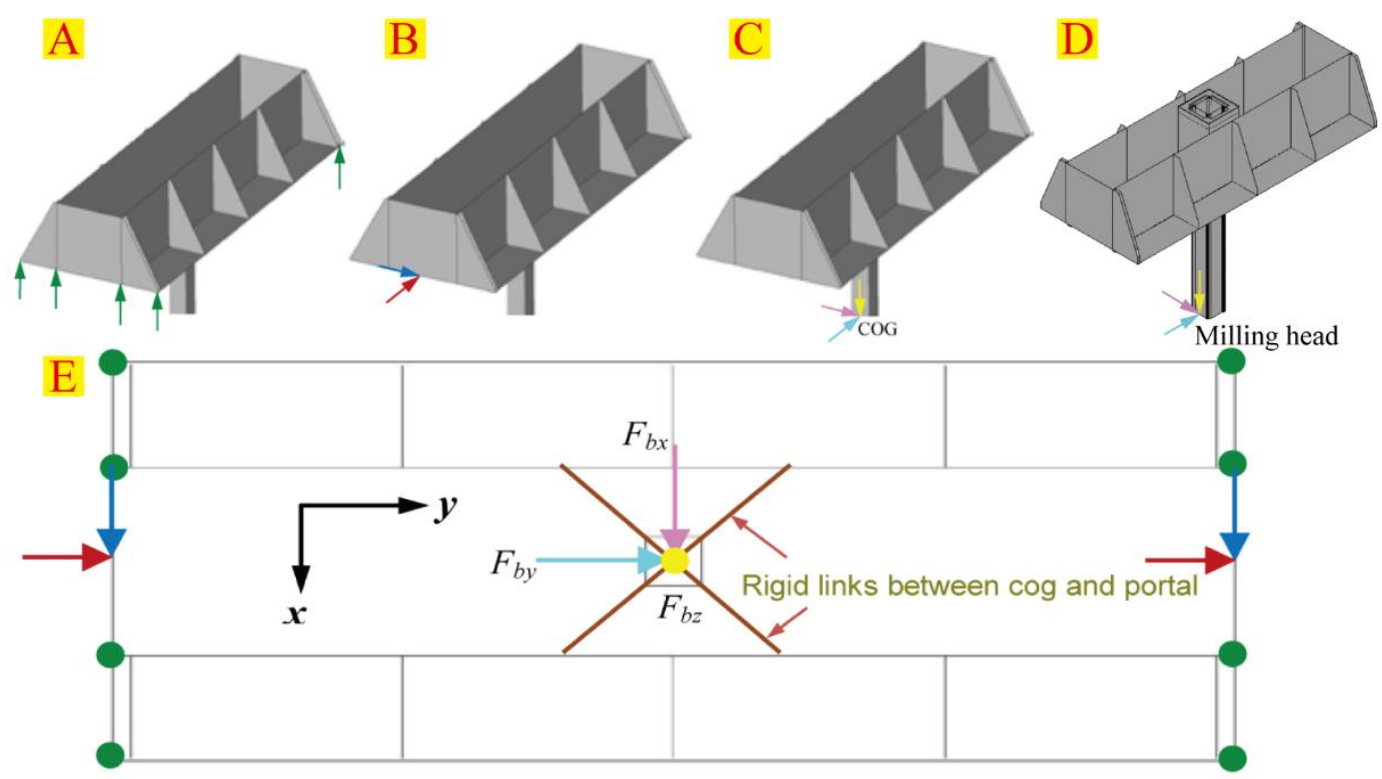

Figure 5. Boundary conditions for composite framework: (A) marked positions of vertical support of the portal; (B) marked positions of horizontal support of the portal; (C) forces direction in the center of gravity (COG) of the traverse and lifting beam; (D) forces direction in milling head; (E) the top view of all boundary conditions. 
A finite element model of the original design of the portal (D0) was first created as shown in Figure 4B. For finite element analysis, aluminum alloy beams were included in the finite element model as beam elements glued to the panel elements. The finite element analysis used small deformations linear-elastic model, in which shell elements adopted four node linear elements Kirchhoff plate theory (in-plane), composite material was with nine node integration trough thickness, beam elements adopted two node linear elements with linear elastic material, and loads (Table 5) and boundary conditions (Figure 5) were used for the simulation analysis. However, the FEA results showed that the displacement of the milling head did not meet the requirements. So, we carried out the structural optimization of the portal. Figure 6 and Table 6 presented a comparison of the portal's performance before and after design optimization.
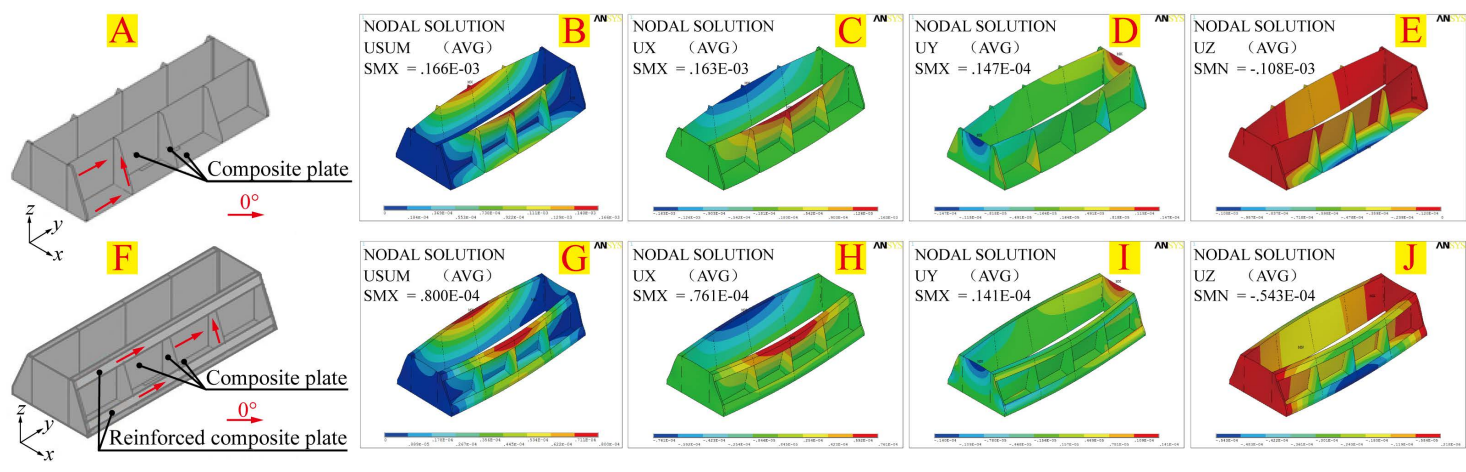

Figure 6. Comparison of the portal's structure and FEA deformation cloud map (taking load 1 as an example) before and after design optimization: (A) structure of D0; (B) total deformation of D0; (C) $x$-direction deformation of D0; (D) $y$-direction deformation of D0; (E) z-direction deformation of D0; (F) structure of D1; (G) total deformation of D1; (H) $x$-direction deformation of D1; (I) $y$-direction deformation of D1; (J) z-direction deformation of D1.

Table 6. Comparison of portal's performance before and after design optimization.

\begin{tabular}{cccc}
\hline Description & & Before (D0) & After (D1) \\
\hline & Total & $\Delta_{\text {total }}=0.166$ & $\Delta_{\text {total }}=0.080$ \\
Maximum deformation (mm) & x-direction & $\Delta_{x}=0.163$ & $\Delta_{x}=0.076$ \\
(Taking Figure 6 as an example) & y-direction & $\Delta_{y}=0.015$ & $\Delta_{y}=0.014$ \\
& z-direction & $\Delta_{z}=0.108$ & $\Delta_{z}=0.054$ \\
\hline Mass & & $100 \%$ & $106 \%$ \\
Stiffness & & $100 \%$ & $189 \%$ \\
\hline
\end{tabular}

From Table 6, it is observed that compared with the structure of D0 before optimization, although the mass of structure D1 after optimization increased by $6 \%$ and the material costs increased by $9 \%$, its stiffness increased by $89 \%$, and the maximum deformation of D1 was much smaller than that of D0. Therefore, the portal structure was optimized as D1.

\subsection{Design Optimization for the Framework}

In the former analysis and determination of the portal structure, a finite element model including the traverse and lifting beam was created to analyze the structural behavior of the composite structure, as shown in Figure 4C. Isotropic aluminum and orthotropic composite materials were used in the analysis of the plates. We used the material specifications for AMPREG21 laminating sandwich panels provided by Gurit (Wattwil, Switzerland). The final design was examined in a detailed finite element analysis, which included all components of the large-scale moving framework. Table 7 lists the analysis results of the maximum displacements of the milling head in 3 coordinate directions after design optimization of the framework. 
Table 7. Maximum displacements of the milling head after design optimization of the framework.

\begin{tabular}{|c|c|c|c|c|}
\hline \multirow{2}{*}{ Position } & \multicolumn{4}{|c|}{ Load Cases } \\
\hline & Load 1 & Load 2 & Load 3 & Load 4 \\
\hline \multicolumn{5}{|c|}{ One of the cloud maps } \\
\hline$\Delta x_{\max }(\mathrm{mm})$ & 0.03 & 0.20 & 0.02 & 0.04 \\
\hline$\Delta y_{\max }(\mathrm{mm})$ & 0.04 & 0.03 & 0.19 & 0.04 \\
\hline$\Delta z_{\max }(\mathrm{mm})$ & 0.19 & 0.18 & 0.18 & 0.20 \\
\hline
\end{tabular}

From Table 7, it is observed that the displacements of the milling head were less than the design requirement of $0.25 \mathrm{~mm}$ in all load cases. Meanwhile, the stress inside the laminate was much lower than the allowable material limits. This indicated that the 3-step design optimization approach proposed in this study for the optimal design of a large-scale moving framework structure was feasible and successful.

\section{Prototype Verification}

To evaluate the performances of the large-scale moving framework, a $40 \mathrm{~m} \times 6 \mathrm{~m} \times 4 \mathrm{~m}$ L5AMC prototype was manufactured. Then, design precision inspections, error compensation, and machining precision tests were carried out to verify the structural integrity of the framework. The actual tests scenes are shown in Figure 7.
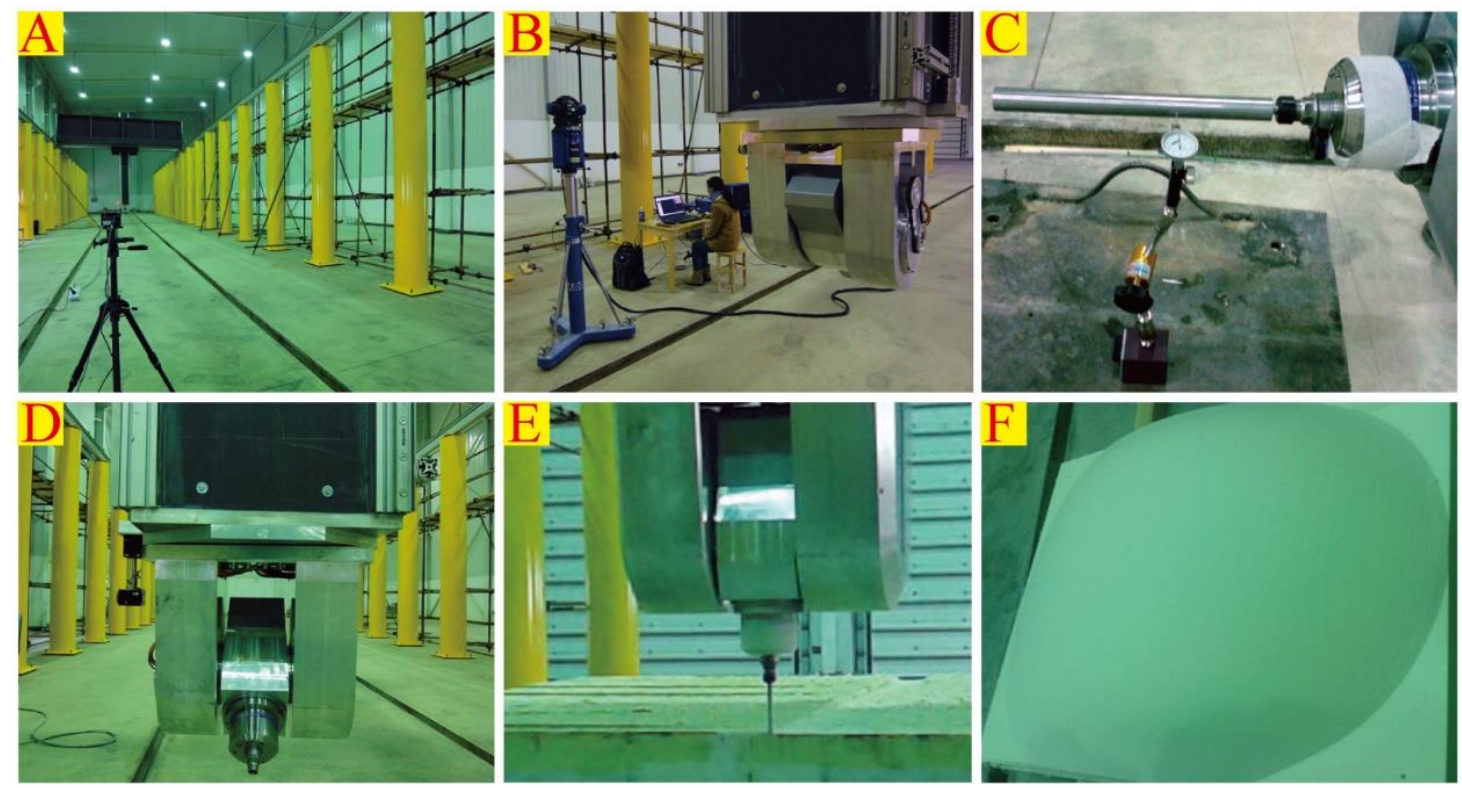

Figure 7. Actual test scenes: (A) inspection of a translational axis using a laser interferometer; (B) inspection of a rotational axis using a laser tracker; (C) milling head inspection; (D) dynamic drive performance inspection; (E) processing test; $(\mathbf{F})$ a processed sample.

Detailed position geometric error modeling, identification, and compensation for the L5AMC prototype have been reported [1]. Table 8 presents some inspection results of the L5AMC prototype related to the framework.

According to the inspection results in Table 8, the large-scale moving framework exhibits a great comprehensive accuracy. Using sandwich structures of composite materials to replace metal materials makes the mass of the framework lightweight. The total mass of the framework with composite materials was $64.57 \%$ compared with metal materials. Zulaika et al. [35] reported $13 \%$ less energy due 
to mass reduction above $20 \%$ in mobile structural components. Therefore, the actual verification results indicated that the large-scale moving framework based on the proposed 3-step design optimization approach fully met the design requirements of the L5AMC and reduced energy consumption.

Table 8. Inspection results of the L5AMC prototype related to the framework.

\begin{tabular}{|c|c|c|c|}
\hline \multicolumn{2}{|r|}{ Test Content } & Design Request & Measured Value \\
\hline \multirow{3}{*}{ Stroke } & $x$ axis $(\mathrm{m})$ & 40 & 40.02 \\
\hline & $y$ axis $(\mathrm{m})$ & 6 & 6.01 \\
\hline & $z$ axis $(\mathrm{m})$ & 4 & 4.01 \\
\hline \multirow{6}{*}{$\begin{array}{l}\text { Positioning } \\
\text { accuracy and } \\
\text { repeatability }\end{array}$} & Translational axes & \multicolumn{2}{|c|}{ Testing equipment: laser interferometer } \\
\hline & \multirow{2}{*}{$\begin{array}{l}\text { Taking the } y \text { axis as an example, maximum } \\
\text { positioning error and repeatability }(\mathrm{mm}) / \text { full stroke }\end{array}$} & \multirow{2}{*}{$0.25 / 0.04$} & Forward: $0.041 / 0.021$ \\
\hline & & & Reverse: $0.148 / 0.028$ \\
\hline & Rotational axes & \multicolumn{2}{|c|}{ Testing equipment: laser tracker } \\
\hline & \multirow{2}{*}{$\begin{array}{l}\text { Taking the } B \text { axis as an example, maximum } \\
\text { positioning error and repeatability }\left({ }^{\circ}\right) / \text { full stroke }\end{array}$} & \multirow{2}{*}{$1 / 0.4$} & $0-110^{\circ}: 0.079 / 0.034$ \\
\hline & & & $-110^{\circ}-0^{\circ}: 0.056 / 0.023$ \\
\hline \multirow{2}{*}{ Sample machining } & Roughness $R_{a}(\mu \mathrm{m})$ & 3.2 & No abnormality, $<3.2$ \\
\hline & Contour accuracy $(\mathrm{mm})$ & \pm 0.05 & No abnormality, $< \pm 0.05$ \\
\hline \multicolumn{4}{|c|}{ Total mass of the framework (kg): 2199.81 (proposed in this study) } \\
\hline \multicolumn{4}{|c|}{3406.92 (Estimation by metal material) } \\
\hline
\end{tabular}

\section{Conclusions}

The present study proposed a design optimization large-scale moving framework approach for an L5AMC to solve the contradiction between the moving mass, material costs, and structural stiffness. Based on the conducted analyses, the following conclusions can be drawn.

1. To design an optimized large-scale moving framework for the L5AMC, an improved approach, named the 3-step design optimization, was introduced to obtain the optimum framework structures based on multi-objective optimization and finite element analysis.

2. The structural stiffness of the framework after optimization increased by $89 \%$ compared with before optimization, although the mass increased by $6 \%$ and the material costs increased by $9 \%$. The finite element simulation results showed that the displacements of the milling head were less than the design requirement of $0.25 \mathrm{~mm}$ in all load cases.

3. The actual verification results indicated that the large-scale moving framework based on the proposed 3-step design optimization approach fully met the design requirements of the L5AMC and reduced energy consumption.

4. The proposed 3-step design optimization approach based on multi-objective optimization and finite element analysis can be considered as a guide for optimizing large-scale moving structures to balance the moving mass, material costs, and structural stiffness.

Author Contributions: G.Z. hosted the project and drafted the present report. P.L. contributed the analysis ideas. X.M. checked the test data. Y.W. carried out the finite element analysis. F.X. conducted the prototype test. And S.Y. proposed the analytical method.

Funding: This work was supported by the State Key Laboratory for Manufacturing Systems Engineering at Xi'an Jiaotong University of China (grant number: sklms2017008), the National Torch Plan of China (grant number: 2012GH040610), and the Jiangsu Kunshan Cultivation Project of Scientific and Technological Achievements of China (grant number: KH1003).

Acknowledgments: This work was supported by the State Key Laboratory for Manufacturing Systems Engineering at Xi'an Jiaotong University of China (grant number: sklms2017008), the National Torch Plan of China (grant number: 2012GH040610), and the Jiangsu Kunshan Cultivation Project of Scientific and Technological Achievements of China (grant number: KH1003). The authors are also grateful to the Kunshan Dynapro Technology Co., Ltd for their support.

Conflicts of Interest: The authors declare no conflict of interest. The founding sponsors had no role in the design of the study; in the collection, analyses or interpretation of data; in the writing of the manuscript; nor in the decision to publish the results. 


\section{Appendix A}

Table A1. Major material parameters used for the framework.

\begin{tabular}{|c|c|c|c|c|}
\hline \multirow{2}{*}{ Parameters } & \multicolumn{2}{|c|}{ Sandwich Panel } & \multirow{2}{*}{$\begin{array}{c}\text { Aluminum Alloy } \\
\text { Plates }\end{array}$} & \multirow{2}{*}{$\begin{array}{c}\text { Aluminum Alloy } \\
\text { Beams }\end{array}$} \\
\hline & $\mathrm{CF}$ & Foam & & \\
\hline Layer mass per unit area, $\rho_{1}\left(\mathrm{~kg} / \mathrm{m}^{2}\right)$ & 0.833 & 1.44 & & \\
\hline Density, $\rho_{2}\left(\mathrm{~kg} / \mathrm{m}^{3}\right)$ & & & 2700 & 3386 \\
\hline Young's modulus, $E \_0^{\circ}(\mathrm{GPa})$ & 134.50 & & & \\
\hline Young's modulus, $E \_90^{\circ}(\mathrm{GPa})$ & 49.90 & & & \\
\hline Young's modulus, $E(\mathrm{GPa})$ & & 0.130 & 75 & 92.75 \\
\hline Shear modulus, G_0_90 (GPa) & 30.90 & & & \\
\hline Shear modulus, G_90_90 (GPa) & 19.20 & & & \\
\hline Poisson's ratio, $v$ & 0.28 & & 0.30 & 0.30 \\
\hline
\end{tabular}

\section{Appendix B}

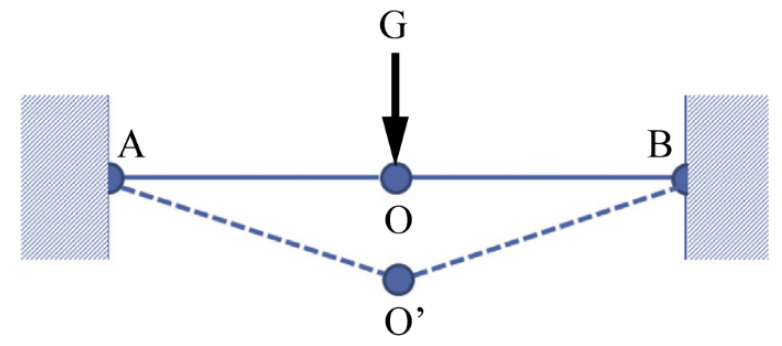

Figure A1. Schematic diagram of "curtain effect" (modified and redrawn from Reference [36]).

Explanation: when the object $\mathrm{AB}$ (e.g., curtain or cable) is large, its center point drops from $\mathrm{O}$ to

$\mathrm{O}^{\prime}$ due to the action of the self-weight $\mathrm{G}$ and generates a deflection. This is called the "curtain effect".

\section{References}

1. Zhong, G.Y.; Wang, C.Q.; Yang, S.F.; Zheng, E.L.; Ge, Y.Y. Position geometric error modeling, identification and compensation for large 5-axis machining center prototype. Int. J. Mach. Tools Manuf. 2015, 89, 142-150. [CrossRef]

2. Wan, M.; Liu, Y.; Xing, W.J.; Zhang, W.H. Singularity avoidance for five-axis machine tools through introducing geometrical constraints. Int. J. Mach. Tools Manuf. 2018, 127, 1-13. [CrossRef]

3. Lv, J.X.; Tang, R.Z.; Tang, W.C.; Liu, Y.; Zhang, Y.F.; Jia, S. An investigation into reducing the spindle acceleration energy consumption of machine tools. J. Clean. Prod. 2017, 143, 794-803. [CrossRef]

4. Li, X.Y.; Lee, C.H.; Hu, P.C.; Zhang, Y.; Yang, F.Z. Cutter partition-based tool orientation optimization for gouge avoidance in five-axis machining. Int. J. Adv. Manuf. Technol. 2018, 95, 2041-2057. [CrossRef]

5. Lee, J.H.; Liu, Y.; Yang, S.H. Accuracy improvement of miniaturized machine tool: Geometric error modeling and compensation. Int. J. Mach. Tools Manuf. 2006, 46, 1508-1516. [CrossRef]

6. Zhang, W.; Lu, B.C.; Fan, G.; Chong, M. Lightweight Design Optimization of Large-Tonnage Hydraulic Press Body Structure. Adv. Mater. Res. 2013, 748, 406-410. [CrossRef]

7. Croccolo, D.; Cavalli, O.; De Agostinis, M.; Fini, S.; Olmi, G.; Robusto, F.; Vincenzi, N. A Methodology for the Lightweight Design of Modern Transfer Machine Tools. Machines 2018, 6, 2. [CrossRef]

8. Yoon, H.S.; Kim, E.S.; Kim, M.S.; Lee, J.Y.; Lee, G.B.; Ahn, S.H. Towards greener machine tools-A review on energy saving strategies and technologies. Renew. Sustain. Energy Rev. 2015, 48, 870-891. [CrossRef]

9. Seifried, R.; Moghadasi, A.; Held, A. Analysis of design uncertainties in structurally optimized lightweight machines. Procedia IUTAM 2015, 13, 71-81. [CrossRef]

10. Law, M.; Altintas, Y.; Phani, A.S. Rapid evaluation and optimization of machine tools with position-dependent stability. Int. J. Mach. Tools Manuf. 2013, 68, 81-90. [CrossRef]

11. Braga, D.F.O.; Tavares, S.M.O.; Silva, L.F.M.; Moreira, P.M.G.P.; Castro, P.M.S.T. Advanced design for lightweight structures: Review and prospects. Prog. Aerosp. Sci. 2014, 69, 29-39. [CrossRef]

12. Kim, D.I.; Jung, S.C.; Lee, J.E.; Chang, S.H. Parametric study on design of composite-foam-resin concrete sandwich structures for precision machine tool structures. Compos. Struct. 2006, 75, 408-414. [CrossRef] 
13. Li, B.T.; Hong, J.; Liu, Z.F. Stiffness design of machine tool structures by a biologically inspired topology optimization method. Int. J. Mach. Tools Manuf. 2014, 84, 33-44. [CrossRef]

14. Kroll, L.; Blau, P.; Wabner, M.; Frie, U.; Eulitz, J.; Klarner, M. Lightweight components for energy-efficient machine tools. CIRP J. Manuf. Sci. Technol. 2011, 4, 148-160. [CrossRef]

15. Li, Y.; Lu, J. Lightweight structure design for wind energy by integrating nanostructured materials. Mater. Des. 2014, 57, 689-696. [CrossRef]

16. Strano, M.; Monno, M.; Rossi, A. Optimized design of press frames with respect to energy efficiency. J. Clean. Prod. 2013, 41, 140-149. [CrossRef]

17. Wu, B.C.; Young, G.S.; Huang, T.Y. Application of a two-level optimization process to conceptual structural design of a machine tool. Int. J. Mach. Tools Manuf. 2000, 40, 783-794. [CrossRef]

18. Wang, L.; Liu, H.T.; Yang, L.; Zhang, J.; Zhao, W.H.; Lu, B.H. The effect of axis coupling on machine tool dynamics determined by tool deviation. Int. J. Mach. Tools Manuf. 2015, 88, 71-81. [CrossRef]

19. Sousa-Martins, J.; Kakogiannis, D.; Coghe, F.; Reymen, B.; Teixeira-Dias, F. Behaviour of sandwich structures with cork compound cores subjected to blast waves. Eng. Struct. 2013, 46, 140-146. [CrossRef]

20. Cerracchio, P.; Gherlone, M.; Sciuva, M.D.; Tessler, A. A novel approach for displacement and stress monitoring of sandwich structures based on the inverse Finite Element Method. Compos. Struct. 2015, 127, 69-76. [CrossRef]

21. Murthy, M.V.V.S.; Renji, K.; Gopalakrishnan, S. A spectral element for wave propagation in honeycomb sandwich construction considering core flexibility. Compos. Struct. 2015, 127, 28-40. [CrossRef]

22. Kim, J.S.; Arronche, L.; Farrugia, A.; Muliana, A.; Saponara, V.L. Multi-scale modeling of time-dependent response of smart sandwich constructions. Compos. Struct. 2011, 93, 2196-2207. [CrossRef]

23. Xiong, J.; Ma, L.; Wua, L.Z.; Li, M.; Vaziri, A. Mechanical behavior of sandwich panels with hollow Al-Si tubes core construction. Mater. Des. 2011, 32, 592-597. [CrossRef]

24. Bartolozzi, G.; Baldanzini, N.; Pierini, M. Equivalent properties for corrugated cores of sandwich structures: A general analytical method. Compos. Struct. 2014, 108, 736-746. [CrossRef]

25. Chang, S.H.; Cheon, S.S. In-plane directional mechanical properties of carbon fabric skins in sandwich structures after thermoforming. Compos. Struct. 2006, 75, 577-581. [CrossRef]

26. Aggogeri, F.; Borboni, A.; Merlo, A.; Pellegrini, N.; Ricatto, R. Vibration Damping Analysis of Lightweight Structures in Machine Tools. Materials 2017, 10, 297. [CrossRef] [PubMed]

27. Manet, V. The use of ANSYS to calculate the behaviour of sandwich structures. Compos. Sci. Technol. 1998, 58, 1899-1905. [CrossRef]

28. Scheff, M. Tragrahmenanordnung, Insbesondere Für ein Mehrachsiges HochgeschwindigkeitsBearbeitungszentrum in Portalbauweise. Deutsches Patent DE102004047525A1, 6 April 2006.

29. Kiridena, V.; Ferreira, P.M. Mapping the effects of positioning errors on the volumetric accuracy of five-axis CNC machine tools. Int. J. Mach. Tools Manuf. 1993, 33, 417-437. [CrossRef]

30. Velea, M.N.; Wennhage, P.; Zenkert, D. Multi-parameter optimisation of vehicle bodies made of FRP sandwich structures. Compos. Struct. 2014, 111, 75-84. [CrossRef]

31. Madeira, J.F.A.; Araújo, A.L.; Soares, C.M.M.; Soares, C.A.M.; Ferreira, A.J.M. Multiobjective design of viscoelastic laminated composite sandwich panels. Compos. Part B 2015, 77, 391-401. [CrossRef]

32. Bandyopadhyay, S.; Saha, S.; Maulik, U.; Deb, K. A Simulated Annealing Based Multi-objective Optimization Algorithm: AMOSA. IEEE Trans. Evol. Comput. 2008, 12, 269-283. [CrossRef]

33. Deb, K.; Pratap, A.; Agarwal, S.; Meyarivan, T. A fast and elitist multiobjective genetic algorithm: NSGA-II. IEEE Trans. Evol. Comput. 2002, 6, 182-197. [CrossRef]

34. Xu, J.Y.; Zhong, G.Y.; Yang, S.F. Improved NSGA-II algorithm and its application in optimization of machining parameters. Comput. Eng. Appl. 2017, 53, 227-234.

35. Zulaika, J.J.; Campa, F.J.; De Lacalle, L.N.L. An integrated process-machine approach for designing productive and lightweight milling machines. Int. J. Mach. Tools Manuf. 2011, 51, 591-604. [CrossRef]

36. Yang, M.; Ahmari, S. Investigation of effect of negative phase of blast loading on cable net curtain walls through the linearized stiffness matrix method. Int. J. Impact Eng. 2013, 61, 36-47. [CrossRef]

(C) 2018 by the authors. Licensee MDPI, Basel, Switzerland. This article is an open access article distributed under the terms and conditions of the Creative Commons Attribution (CC BY) license (http:/ / creativecommons.org/licenses/by/4.0/). 